\title{
La historia del arte es una profesión imprescindible en la tutela del patrimonio histórico
}

José Castillo Ruiz | profesor titular del Departamento de Historia del Arte de la Universidad de Granada

URL de la contribución <www.iaph.es/revistaph/index.php/revistaph/article/view/3447>

\begin{abstract}
Exordio. Destellos e impresiones que retratan la situación profesional de la historia del arte ${ }^{1}$

La historia del arte es uno de los saberes humanísticos que mejor ha definido su condición científica y disciplinar, convirtiéndose en un instrumento fundamental para el conocimiento de la cultura humana. Su condición histórica e interdisciplinar le ha permitido ir mutando en función de las exigencias de la historicidad, dando cabida a nuevos objetos de estudio (derivados de la ampliación del concepto de arte) y, sobre todo, a nuevas orientaciones marcadas por la cambiante función social desempeñada por el arte.
\end{abstract}

En este devenir científico, la asimilación de la condición patrimonial de los bienes artísticos se ha convertido en uno de los más importantes retos disciplinares para la historia del arte, al situarla ante dos de sus históricas responsabilidades: el compromiso social de pronunciarse ante un objeto (pensemos en los monumentos) con fuertes implicaciones simbólicas, sociales o urbanísticas; y la necesidad de ofrecer a sus egresados una formación profesional que haga posible y creíble esta responsabilidad social.

Aunque este posicionamiento patrimonialista está presente en la historia del arte prácticamente desde sus inicios (HERNÁNDEZ MARTíNEZ, 2000), ocupando incluso un papel protagonista en la conformación de los instrumentos administrativos y normativos de la tutela en España, en los últimos años, precisamente cuando el patrimonio histórico ha dado un salto cualitativo y cuantitativo, científica y profesionalmente, la historia del arte, que partía de la centralidad de la tutela, se ha visto incomprensiblemente relegada a un papel muy secundario y confuso ${ }^{2}$. Refugiada en una distante superioridad epistemológica no ha sabido responder a la potente irrupción de nuevas disciplinas muy profesionalizadas y,
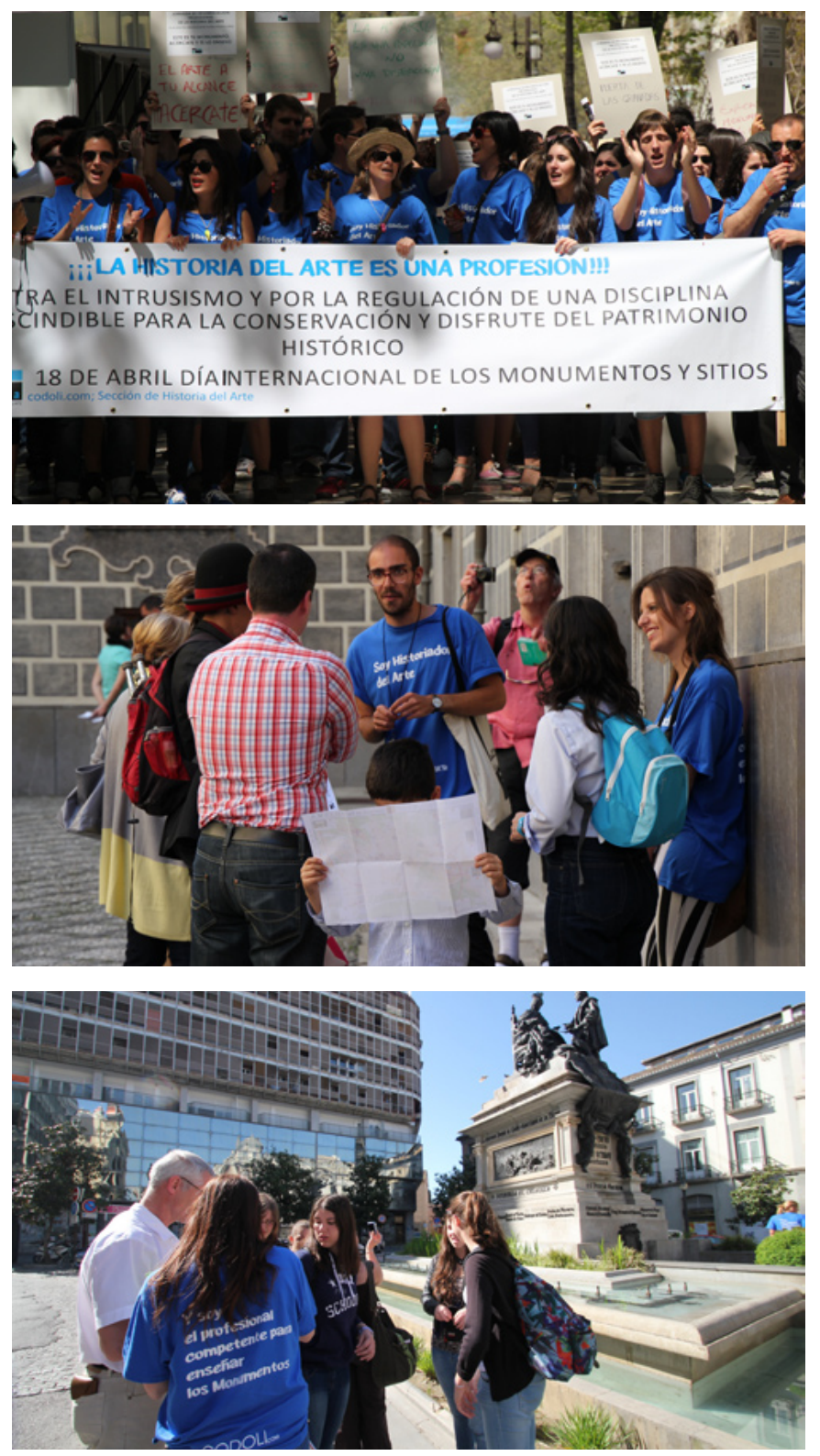

Jornada de reivindicación profesional de la historia del arte promovida por el CODOLI, sección de historia del arte (Granada, 18 de abril de 2013)

| fotos Ximena Hidalgo 
a debate Historiadores del arte ¿para qué? Una titulación en busca de una profesión | coordina José Castillo Ruiz

sobre todo, a la dilución de nuestro objeto de estudio (el patrimonio histórico-artístico), del que hemos aceptado, de nuevo incomprensiblemente, que se le califique continuamente de obsoleto, antiguo o retrogrado desde diferentes ámbitos del patrimonio histórico, propiciando con ello la desconsideración del mismo y, por extensión, de nuestra disciplina. En este sentido, conviene recordar que los bienes histórico-artísticos no sólo constituyen, y de forma muy mayoritaria, el grueso del patrimonio histórico declarado en nuestro país, sino que conforman los recursos culturales turísticos que más visitantes y desarrollo generan, sin olvidar que son los bienes culturales más apreciados y valorados por la sociedad.

La historia del arte necesita por tanto hacer un ejercicio de autoafirmación científica y disciplinar y volver a reclamar un papel central en la tutela como corresponde al que ocupa el patrimonio histórico-artístico dentro de los bienes culturales. Y para recuperar esta centralidad ya no basta argüir la honorabilidad y el prestigio de una disciplina de gran trayectoria y significación histórica como la nuestra, sino que exige aportar fundamentos, métodos y herramientas a nuestros historiadores para que puedan abordar con garantías y credibilidad las demandas profesionales de la tutela. Y siempre desde el principio de interdisciplinariedad consustancial a este campo, el cual obviamente defendemos aunque desde el respeto a las atribuciones competenciales de cada disciplina, las cuales deberían asumir y reproducir la jerarquización de valores y bienes existentes en la realidad patrimonial.

Pero no sólo basta con conocimiento y capacitación, la historia del arte necesita, al igual que lo están haciendo otras disciplinas, definir formalmente, normativamente, su participación en la protección del patrimonio histórico.
Y debe hacerlo en dos sentidos: clarificando cuál es su objeto de estudio, es decir, definiendo formalmente el concepto de patrimonio histórico-artístico; y delimitando las acciones tutelares sobre las que somos competentes. En este último aspecto ya no basta tampoco recluirnos en la cada vez menos atendida catalogación o declaración de bienes, sino que reclamamos nuestra competencia en todas aquellas acciones que impliquen análisis o valoración de los objetos histórico-artísticos: exportación, expolio, tasación, restauración, rehabilitación... y muy especialmente difusión. En este caso, la exclusividad laboral reclamada por los guías turísticos por ejemplo en Andalucía, con independencia de su legalidad o no, resulta ofensivo para la historia del arte y una inaceptable pérdida de oportunidades laborales.

Pero más importante que todo lo aquí reclamado es la urgencia y necesidad de que los historiadores del arte nos convenzamos de que, con independencia de la actividad que desempeñemos (incluso parados), la historia del arte es una profesión y los historiadores del arte unos profesionales que, como cualquier otros, tenemos unos derechos cuyo cumplimiento debemos reclamar en todo momento y en todos los ámbitos.

Ante esta situación, desde el SEPHA (Sección Propia de Historia del Arte del Colegio Oficial de Doctores y Licenciados en Filosofía y Letras y Ciencias de Granada, Jaén y Almería) hemos planteado a la administración cultural andaluza una propuesta de reconocimiento profesional de la historia del arte que, con independencia del preciso y completo encaje legal y administrativo del mismo, se asienta en una serie de premisas que consideramos perfectamente válidas como principios para el desempeño de nuestra actividad profesional en el campo de la tutela del patrimonio histórico y que son las que vamos a exponer aquís. 
a debate Historiadores del arte ¿para qué? Una titulación en busca de una profesión | coordina José Castillo Ruiz

\section{Estrategias para el reconocimiento profesional de la historia del arte. La reglamentación normativa de nuestras funciones y competencias.}

Al margen de las muchas carencias o deficiencias metodológicas y formativas que la disciplina de la historia del arte deba superar para poder tener una presencia adecuada en el campo patrimonial, consideramos que el mecanismo más importante para conseguir un reconocimiento digno de nuestra actividad profesional en el ámbito de la protección es proceder a una reglamentación legal y administrativa de las competencias y responsabilidades de nuestra disciplina, en cada una de las acciones y ámbitos patrimoniales que le correspondan. Sólo así conseguiremos superar esta situación, ciertamente inexplicable y sorprendente de la historia del arte, en la cual una disciplina tan relevante en el ámbito del patrimonio histórico, con tan larga trayectoria en este campo y tan preparada para afrontar las exigencias demandadas por la protección, haya quedado relegada a un lugar tan menor como el que el propio Instituto Andaluz del Patrimonio Histórico le reconoce cuando procede a definir las profesiones del patrimonio histórico: "Hay titulaciones universitarias, como es el caso de historia del arte, que no tienen reflejo profesional como tal, sino que su presencia en el mercado de trabajo está sujeta a la especialización en alguna de las profesiones de las categorías anteriores"4. Desde luego una definición ciertamente injusta y no acorde con la realidad, y que, a través del debate generado en este número de revista ph, esperemos retiren de su página web.

De ahí que la referida propuesta de reglamento haya sido la vía elegida por el Colegio profesional de Granada para la defensa de nuestra profesión, cuyas premisas fundamentales son las siguientes:

A) Reconocimiento de la metodología de la historia del arte como una metodología científica equiparable en igualdad de condiciones a cualquier otra de las disciplinas concurrentes en el patrimonio histórico.

La historia del arte, si bien es una disciplina científica de carácter humanístico, dispone de numerosas metodolo- gías de estudio, tal y como nos encargamos de explicar con ahínco a nuestros estudiantes en las asignaturas de historiografía. Esta sucesión (o concurrencia) de métodos (social, iconológico, formalista, cultural, etc.) provoca cierta confusión y una indeseable relativización de la cientificidad de nuestro método, muy perjudicial cuando nos sometemos a un proceso formalizado y de fuertes implicaciones sobre la realidad física y social de nuestros objetos, como sucede con la actividad tutelar.

Desde nuestra perspectiva, consideramos que el reconocimiento formal o legal de nuestra metodología debe hacerse en referencia a la propia historia del arte como tal método científico. Esta es la definición que hacemos en nuestra propuesta de reglamento: "Se entiende por metodología histórico-artística aquella considerada como propia por la disciplina de la historia del arte, en particular todos aquellos métodos de estudio desarrollados sobre una obra de arte con el objetivo de identificar sus cualidades artísticas y significación histórica desde diferentes perspectivas (formalista, estilística, histórica, técnico-material, iconográfica, sociológica, biográfica, etc.)" (CASTILLO RUIZ; GÓMEZ JIMÉNEZ, 2009: 2). Esta orientación nos permite además incorporar en nuestro bagaje metodológico aquellas exigencias de la tutela que, como aplicación de la interdisciplinariedad, resultan imprescindibles para abordar el estudio de los bienes histórico-artísticos (con independencia o no de que podamos convertir incluso en opción metodológica, a la par de las definidas históricamente, la orientación patrimonialista).

Estas exigencias son fundamentalmente las siguientes:

- Concesión de una mayor importancia a la dimensión histórica de los objetos artísticos, reconociendo la complejidad de los mismos derivada de esta evolución histórica. Si bien la diacronía está plenamente asumida por nuestra disciplina, el reconocimiento y valoración de la misma en un bien determinado no están plenamente logrados, imperando por lo general una jerarquización histórica derivada de una concepción demasiado estilística de la historia del arte y en la que se prima el momento originario de la construcción o creación (y 
a debate Historiadores del arte ¿para qué? Una titulación en busca de una profesión | coordina José Castillo Ruiz

en la que se define el estilo principal), lo cual acaba derivando en posiciones patrimonialistas cercanas al repristino o la restauración estilística (prohibidas por la legislación).

- Liquidación de las categorías artísticas y de la distinción entre técnicas artísticas. Esto es apreciable, especialmente, en los bienes inmuebles, donde la remisión del bien a su condición histórica propicia que la diversidad de objetos que lo conforman (pintura, escultura, retablos, rejas, etc.) se entiendan como una unidad para su protección y, por tanto, para su estudio y valoración. A esto hay que unir la vinculación de los bienes, especialmente los de naturaleza inmueble (aunque no sólo ellos) al medio, al lugar donde fueron construidos.

- Reconocimiento de su condición patrimonial. El estudio de un objeto artístico no puede concluir con el último periodo en el que se hayan adicionado elementos de valor, sino que debe continuar con el análisis de aquellas actuaciones y contenidos que han determinado su consideración como patrimonio histórico, así como los derivados de la adquisición de esta condición: valores y significados, restauraciones, grado de protección existente o posible, posibilidades de uso y disfrute del bien, estado de conservación, etc. De este reconocimiento de la condición patrimonial se deriva la necesidad de entender el conocimiento histórico-artístico con un carácter instrumental o aplicado, lo que nos exige el manejo de una serie de herramientas y técnicas de análisis y representación (levantamiento de planos, realización de catas ${ }^{5}$, etc.), así como la necesaria emisión de un juicio crítico sobre el bien o la acción tutelar objeto de estudio ${ }^{6}$.

B) Consideración de los bienes histórico-artísticos como un grupo patrimonial diferenciado y con entidad propia. El concepto de patrimonio histórico-artístico.

Uno de los grandes problemas que se encuentra la historia del arte a la hora de participar en las tareas de protección es que no sabe cuáles son los bienes sobre los que puede actuar, hecho este hasta ridículo si tenemos en cuenta que todo el mundo sabe (utilizamos esta expresión coloquial intencionadamente y por tanto con un sentido científico como sinónimo de socialización) que los historiadores del arte nos ocupamos de los monumentos, las obras de arte, los museos de arte y demás objetos de valor artístico, es decir, de la mayoría de bienes que conforman nuestro patrimonio histórico. En este sentido quiero poner en valor (nunca mejor dicho) los resultados del primer estudio de percepción y conocimiento social del patrimonio histórico realizado en España, entre los cuales cabe destacar que la ciudadanía española, cuando se les pregunta qué entienden por patrimonio histórico responden, de una forma muy mayoritaria, que monumentos (MORATE MARTíN, 2012).

Sin embargo, si descendemos a la realidad patrimonial formal, a la definida en la legislación de patrimonio histórico, nos encontramos con que los monumentos (u otras tipologías propiamente histórico-artísticas como los jardines históricos o los conjuntos históricos) están caracterizados por diversidad de valores en los que el artístico queda completamente diluido; situación ésta concordante con el hecho de que no exista un reconocimiento singular como tal masa patrimonial del patrimonio histórico-artístico.

Efectivamente, si observamos las diferentes leyes de patrimonio histórico existentes en nuestro país nos encontramos con que no existe el concepto de patrimonio histórico-artístico. Esto contrasta con el hecho de que sí se reconocen formalmente otros patrimonios como el arqueológico, el etnológico o el industrial. La razón que explica esta situación es el hecho de que el concepto de patrimonio histórico-artístico, que era el utilizado tradicionalmente en nuestra legislación para definir el conjunto de bienes susceptibles de proteger, se considera como un concepto obsoleto y superado (en cuanto concepto global) por lo que ha sido sustituido por otros de mayor amplitud como el de patrimonio histórico o patrimonio cultural.

Esto ha provocado una situación realmente injusta para los objetos histórico-artísticos, ya que, por un lado, han 
a debate Historiadores del arte ¿para qué? Una titulación en busca de una profesión | coordina José Castillo Ruiz
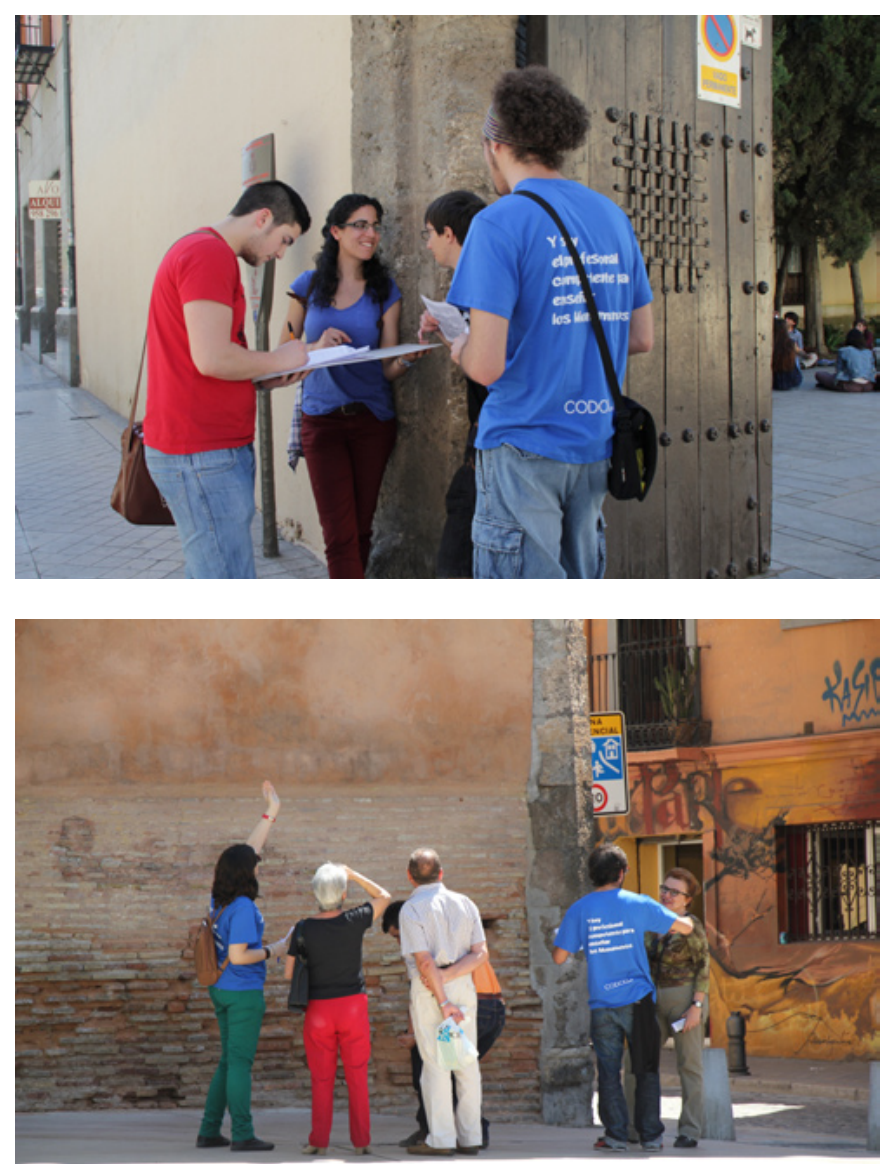

Historiadores del arte enseñando gratuitamente diversos monumentos de Granada, durante la jornada del pasado 18 de abril | fotos Ximena Hidalgo

dejado de identificar al conjunto del patrimonio histórico pero, por otro lado, no han sido reconocidos como un tipo de patrimonio específico dentro de ese nuevo concepto de patrimonio histórico o cultural, por lo que quedan en un limbo conceptual muy confuso.

Si bien no existe el concepto de patrimonio históricoartístico, sí aparece reconocido en la legislación el valor artístico que sería, en principio, el valor sobre el que seríamos competentes los historiadores del arte.

Este valor artístico, si bien está presente en la caracterización general del concepto de patrimonio histórico, así como en las definiciones de muchos tipos de bienes, sin embargo aparece asociado por lo general a muchos otros valores (histórico, técnico, científico, industrial, etnológico, etc.), lo cual acaba diluyendo su importancia y consideración en el conjunto de valores reconocidos. Sin embargo, esta consideración igualitaria de valores contrasta con el hecho de que la mayoría de bienes culturales formalmente declarados en nuestro país (predominio absoluto de la categoría BIC, tipología monumento) corresponden a bienes estudiados por la historia del arte (MARTíNEZ YÁÑEZ, 2010). A esto hay que añadir que no existe un reconocimiento expreso del valor histórico-artístico (el valor histórico es otro de los reconocidos legalmente de forma singular) aunque se entiende que el valor artístico (como el resto de valores industrial, científico, arqueológico, etc.) tiene que ser valorado desde una perspectiva histórica, por lo que podemos hacer una identificación entre el valor artístico y el histórico-artístico. En relación al valor artístico, quisiéramos apuntar una tendencia que se lleva percibiendo desde hace años como es la paulatina fragmentación y disgregación de nuestro objeto de estudio y su consiguiente apropiación por otras disciplinas a raíz del reconocimiento legal de nuevos valores culturales. Si bien esto resulta incontestable y hasta legítimo, consideramos que la historia del arte no está sabiendo afrontar ni defender su posición respecto a este proceder. Sucede en varios casos:

- Sucede con el patrimonio etnológico, material e inmaterial, donde los límites entre el valor artístico o el puramente etnológico son muy difíciles de fijar, por ejemplo, en la arquitectura popular o rural.

- Sucede también con el patrimonio industrial, de reciente incorporación en el ordenamiento jurídico. En este caso, la falta de una disciplina específica está permitiendo que los historiadores del arte tengamos una mayor presencia.

- Sucede así mismo con el patrimonio arquitectónico contemporáneo, donde la disciplina de la arquitectura, por su relación con la práctica arquitectónica contemporánea, reclama su legitimidad para el estudio y actuación. Aunque 
a debate Historiadores del arte ¿para qué? Una titulación en busca de una profesión | coordina José Castillo Ruiz

el valor arquitectónico aparece recogido en muchas leyes de patrimonio histórico (Cataluña, Galicia, Valencia, Madrid, Cantabria, Islas Baleares, Aragón, Canarias, Extremadura, Castilla y León, La Rioja y Navarra), no así en la ley nacional y andaluza, no nos parece acertado, ya que se trata de un valor contenido en el artístico, lo mismo que sucede con otros hipotéticos valores, como el pictórico o escultórico, que podrían reclamar también disciplinas de bellas artes.

- Sucede finalmente con el patrimonio arqueológico, donde la legitimidad (y legalidad) que otorga a los arqueólogos el dominio de la metodología arqueológica, imprescindible para estudiar estos bienes, está propiciando, ante la carencia de herramientas por parte de otras disciplinas, especialmente la historia del arte, su extensión hacia las emergencias arquitectónicas (a través de la legítima pero a veces extralimitada, estratigrafía muraria). A esto hay que añadir nuestra exclusión del estudio de los objetos artísticos hallados en las excavaciones arqueológicas, hecho éste extensible a las artísticas pinturas rupestres.

Ante esta situación, la historia del arte debe reclamar que se determinen cuáles son los bienes culturales que nos competen como disciplina. En definitiva, hay que definir qué es el patrimonio histórico-artístico. Ésta es la definición realizada por el SEPHA en la propuesta de reglamento que estamos comentando: "El patrimonio histórico-artístico estaría formado por todos aquellos bienes muebles e inmuebles, materiales e inmateriales, que dispongan de valor artístico o estético". A partir de dicha definición, los tipos de bienes que integrarían el patrimonio histórico-artístico serían los siguientes: "Está conformado por todas aquellas tipologías y clases de bienes muebles, inmuebles o inmateriales establecidas en la ley para la inscripción de un bien en el Catálogo General del Patrimonio Histórico o en el Inventario de Bienes Reconocidos del Patrimonio Histórico de Andalucía en las que se reconozca el valor artístico o estético como constitutivo de las mismas. También forman parte del patrimonio histórico-artístico aquellas tipologías que, si bien no incluyen de forma expresa los valores artístico o

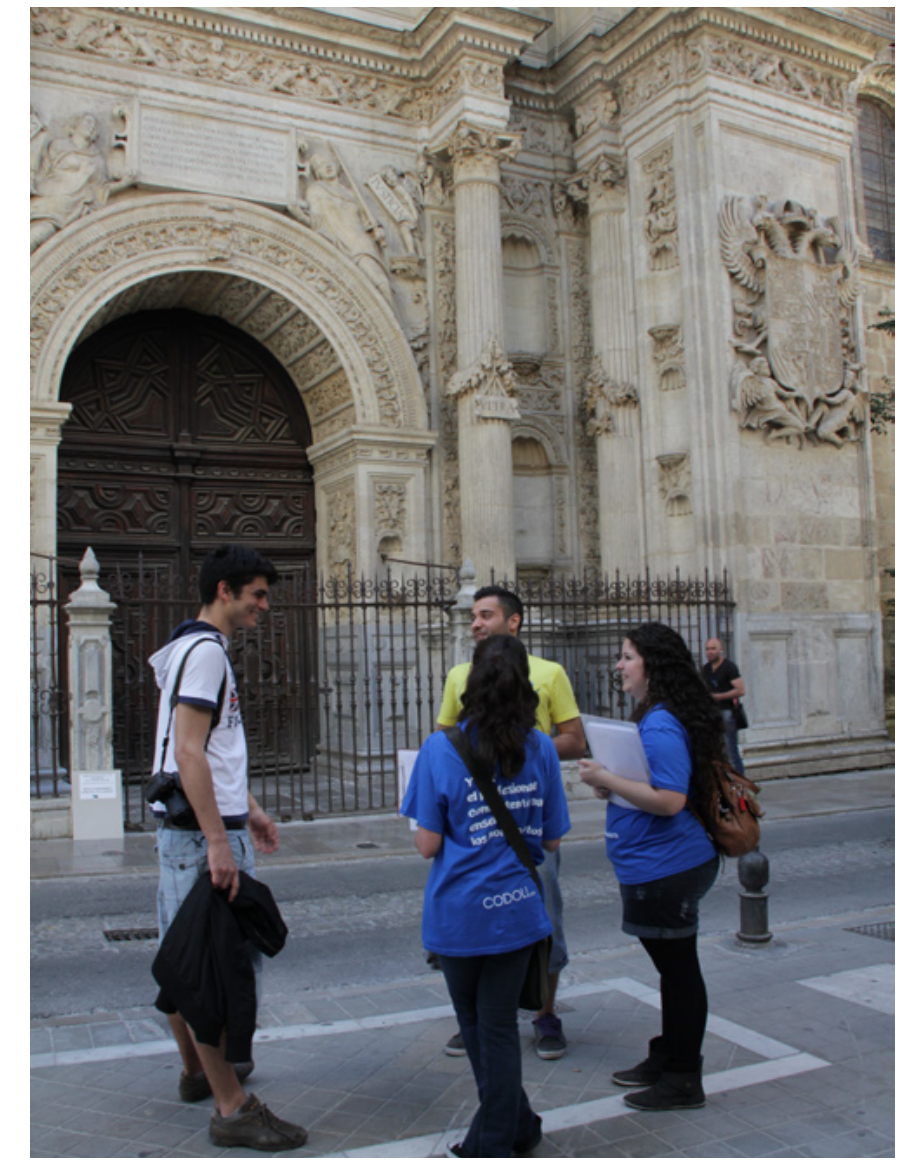

Jornada de reivindicación profesional de la historia del arte, conocida como Marea azul (18 de abril de 2013) | foto Ximena Hidalgo

estético, incorporan bienes que son objeto de estudio de la historia del arte, tal y como sucede con algunos bienes integrantes del patrimonio industrial, etnológico o bibliográfico" (CASTILLO RUIZ; GÓMEZ JIMÉNEZ, 2009: 2).

C) Participación de la historia del arte en todas aquellas acciones tutelares realizadas sobre los bienes históricoartísticos que impliquen descripción, análisis históricoartístico y valoración.

Junto con la identificación de los bienes culturales, que son de nuestra competencia, la otra gran indefinición existente en torno a la historia del arte es la referida al tipo de contenidos o estudios que puede y debe abordar y en qué actividades tutelares en concreto. 
a debate Historiadores del arte ¿para qué? Una titulación en busca de una profesión | coordina José Castillo Ruiz

Desde nuestro punto de vista (y es lo que hemos recogido en la propuesta del SEPHA), esta fijación precisa de nuestra participación en el ámbito tutelar debería concretarse a través de estas premisas:

- Determinación de nuestra competencia profesional exclusiva e intransferible en relación al estudio de los bienes histórico-artísticos en tres ámbitos: descripción formal, análisis histórico-artístico y valoración patrimonial (CASTILLO RUIZ; GÓMEZ JIMÉNEZ, 2009: 3). Estas atribuciones circunscriben con precisión y claridad nuestra participación a aquellos cometidos propios de nuestra disciplina y marca los límites y parámetros a partir de los cuales nos relacionamos con el resto de disciplinas requeridas tanto para el estudio (en este caso dentro del conjunto de investigaciones denominadas "estudios previos") como para la actuación en un determinado bien.

- Participación de la historia del arte en todas aquellas acciones tutelares realizadas sobre los bienes históricoartísticos que impliquen descripción, análisis históricoartístico y valoración. A las tradicionales y obvias de catalogación o difusión debemos unir cualquiera otras que supongan una incidencia directa o indirecta sobre el valor artístico del bien: exportación, compra-venta, tasación, colocación de carteles y rótulos, restauración, rehabilitación, expolio, etc.

- La formalización de nuestra participación a través de la emisión de un preceptivo y reglamentado informe histórico-artístico, el cual deberá adaptarse a la actividad de protección de que se trate. Al respecto, en nuestra propuesta de reglamento, distinguimos varios tipos de informes: informe histórico-artístico de catalogación, de intervención, de difusión, de peritación y de expertización. Esta es la definición de informe que hacemos en dicha propuesta: "Se entiende por informe histórico-artístico el documento técnico-científico en el que se analizan y describen los elementos y contenidos artísticos de un bien en su contexto histórico, tanto los originarios como los incorporados a lo largo de su evolución histórica, con el objetivo de identificar los valores patrimoniales susceptibles de protección. Su formalización podrá reali- zarse en cualquier formato convencional o electrónico y deberá cumplir cuantas exigencias formales, procedimentales o de contenido establezca el colegio profesional o sección de historiadores del arte. Todo informe histórico-artístico contendrá obligatoriamente contenidos de descripción, análisis y valoración del objeto artístico. Igualmente todos los informes deberán incluir un dictamen que determine con claridad y precisión las determinaciones o recomendaciones del mismo. La diferencia entre los diferentes tipos de informes radicará en el objetivo exigido por la actividad tutelar a desarrollar sobre el bien" (CASTILLO RUIZ; GÓMEZ JIMÉNEZ, 2009: 3).

La existencia normalizada de estos informes (con lo que ello implica de definición, aprendizaje, divulgación, aplicación y validación de sus contenidos) es esencial para el desarrollo profesional de la historia del arte. Necesitamos que todos los agentes que participan en el proceso patrimonial, especialmente la administración, sepan con claridad cuál es nuestro cometido en este campo y ese debe ser, al margen de otras competencias más generales que ahora referiremos, el de la elaboración de informes histórico-artísticos, de los cuales es importante y necesario incluso hasta el nombre, pues la diversidad de términos existentes para referirse a él (estudio o informe histórico; estudio o informe histórico constructivo; estudio o informe documental, etc.) no hacen más que menoscabar nuestro rigor científico y facilitar el intrusismo profesional.

D) Participación de los historiadores del arte, y en proporción al número de bienes histórico-artísticos tutelados, en todas aquellas instituciones $u$ organismos encargados de la gestión y protección de bienes culturales de valor histórico-artístico, así como en todos aquellos planes o programas que afecten a los mismos.

Si bien obviamente existen historiadores del arte en aquellas instituciones ejecutivas o consultivas encargadas de la tutela (Ministerio, consejerías de cultura y delegaciones provinciales de cultura, comisiones de patrimonio histórico, organismos autónomos de gestión de ciuda- 
a debate Historiadores del arte ¿para qué? Una titulación en busca de una profesión | coordina José Castillo Ruiz

des históricas, conjuntos monumentales, arqueológicos, institutos de patrimonio o de restauración, etc.), y además solemos participar en todo tipo de instrumentos y planes urbanos o territoriales, así como de gestión y planificación; dicha participación (al margen de que es claramente deficiente) debería serlo de un modo formalizado, en el cual nuestra presencia fuera, además de obligada, proporcional al número de bienes históricoartísticos objeto de tutela, ordenación o planificación.

Un ejemplo significativo al respecto es la cuestión de los catálogos urbanísticos. Los catálogos de los planes especiales y generales, por circunscribirnos a los que suelen aplicarse sobre los conjuntos históricos, resultan fundamentales para determinar el tipo y nivel de protección de una ciudad histórica, es decir, delimitan de forma muy precisa y permanente los derechos de los titulares de los inmuebles de dicha ciudad. Se trata por tanto de un trabajo de una gran responsabilidad que es exigible tanto al equipo redactor como, sobre todo, a la administración de cultura supervisora del plan. Al margen de las deficientes condiciones en la que se suelen hacer estos trabajos de catalogación en los planes (que no es achacable a los profesionales que lo hacen, no siempre historiadores del arte), lo que resulta inexplicable es que no exista una comprobación de cada una de las fichas de catálogo por parte de la administración para validar o no su idoneidad (lo mismo que se hace obviamente con los yacimientos arqueológicos o con los proyectos de restauración). El argumento de que existe un número elevadísimo de bienes catalogados (sobre todo edificios), lo que hace casi imposible su control, no es admisible ni tolerable en un proceso tutelar mínimamente riguroso y científico, lo cual resulta lesivo no sólo para la tutela sino para los intereses profesionales de los historiadores del arte, los cuales tienen en este ámbito un campo profesional muy importante.

En conclusión, y después de todo lo expuesto, quisiéramos señalar que la historia del arte es una disciplina científica perfectamente preparada metodológica y formativamente para afrontar todas las exigencias tutelares a desarrollar sobre los bienes histórico-artísticos que impliquen conocimiento y valoración de los contenidos y elementos artísticos de dichos bienes, de ahí que sea legítimo y justo reclamar una reglamentación normativa de nuestras competencias y funciones en el campo de la protección del patrimonio histórico. De esta forma, no sólo conseguiríamos potenciar y defender el desarrollo profesional y la inserción laboral de nuestros titulados, sino sobre todo, mejorar la calidad de los procesos tutelares y con ello el interés general de todos los ciudadanos. 


\section{NOTAS}

1. Este primer epígrafe de la aportación del profesor Castillo Ruiz, coordinador de la sección, fue utilizado como texto de presentación y apertura del debate (pp. 204-205).

2. Y ello a pesar de que pronto empezó a posicionarse en este campo, tal y como lo reflejan las pioneras jornadas organizadas por el Comité Español de Historia del Arte y el Instituto Andaluz de Patrimonio Histórico y celebradas en Cádiz del 17 al 19 de junio de 1992 bajo el título Historia del Arte y Bienes Culturales, a las que le siguieron muchas otras (BORRÁS GUALIS, 2013: 59).

3. Esta propuesta consiste en la inclusión de un título sobre patrimonio histórico-artístico en el Reglamento, actualmente en proceso de debate, que desarrolle la Ley 14/2007 de 26 de noviembre de patrimonio histórico de Andalucía. Una valoración y reproducción de esta propuesta se puede consultar en CASTILLO RUIZ; GÓMEZ JIMÉNEZ, 2009.

4. <http://www.iaph.es/web/canales/formacion/orientacion-profesional/ profesiones/>.

5. La realización de catas incluida en nuestra propuesta de reglamento no debe entenderse como una injerencia en otros ámbitos competenciales ni, por supuesto, es equiparable o sustitutiva de la estratigrafía muraria. Se trata simplemente de una técnica más de investigación relacionada con la reclamación que hacemos de convertir también el objeto artístico a intervenir en una importante fuente de información (y no sólo las fuentes tradicionales bibliográficas, archivísticas o de otro tipo) y que tiene como objetivo exclusivo verificar o posibilitar el informe histórico-artístico (y no otros objetivos como podrían ser la investigación arqueológica, la identificación de problemas estructurales o el análisis profundo del estado de conservación).

6. En esta misma línea de exigir a la historia del arte una adaptación metodológica a las exigencias de la tutela, véase GARCÍA CUETOS, 2012: 92-98.

\section{BIBLIOGRAFÍA}

- BORRÁS GUALís, G. M. (2013) Historia del Arte y Patrimonio Cultural: una revisión crítica. Zaragoza: Prensas universitarias, 2013

- CASTILLO RUIZ, J.; GÓMEZ JIMÉNEZ, J. (2009) Propuesta para una reglamentación legal de la actividad profesional de la Historia del Arte en el campo de la protección del Patrimonio Histórico. e-rph, diciembre 2009, n.o 5, pp. 1-4<http://www. revistadepatrimonio.es/revistas/numero5/estudiosgenerales/ experiencias/articulo.php>

- GARCíA Cuetos, M. P. (2012) El Patrimonio Cultural. Conceptos básicos. Zaragoza: Prensas Universitarias de Zaragoza, 2013, pp. 92-98

- HERNÁNDEZ MARTÍNEZ, A. (2000) ¿Qué hace una chica como tú en un sitio como éste? (Algunas reflexiones acerca de la relación entre la Historia del Arte y el Patrimonio Cultural). Artigrama, n. ${ }^{\circ} 15$, pp. 543-564

- HISTORIA del Arte y Bienes Culturales. Sevilla: Consejería de Cultura de la Junta de Andalucía, Instituto Andaluz de Patrimonio Histórico, 1998 (Colección PH Cuadernos; 8)

- MARTÍNEZ YÁÑEZ, C. (2010) La construcción formal de la realidad patrimonial española: la catalogación. En HENARES CUÉLLAR, I. (dir.) La protección del Patrimonio Histórico en la España democrática. Granada: Universidad, Caja Madrid, 2010, pp. 91-130

- MORATE MARTíN, G. (dir.) (2012) Conocimiento y percepción del Patrimonio Histórico en la sociedad española. Madrid: Caja Madrid, 2012 